\title{
Influence of Grassland Gap on Seedling Establishment of Leymus chinensis (Trin.) Tzvel.
}

Authors are ${ }^{1}$ Associate Professor, College of Life Science, Hebei University, Wusi Donglu 180, Baoding. 071002, China; ${ }^{2}$ Professor, Institute of Grassland Science, China Agricultural University, Yuanmingyuan Xilu 2, Haidian District, Beijing, 100094, China.

\begin{abstract}
A field study was conducted to investigate the effects of existing adult neighbors and gap size on the process of seedling establishment in Leymus chinensis. Seeds of L. chinensis were added to artificially created gaps in a degraded steppe in North China. Neighbor root exclusion was accomplished using polyvinyl chloride tubes sunk in the soil of gaps. Seedling emergence and survivorship was greater in gaps than in control areas, but growth performance was higher only in larger gaps $(20 \mathrm{~cm}$ and $40 \mathrm{~cm}$ in diameter) with neighboring roots present and in all gaps without neighboring roots present. Seedlings produced no tillers in the control and few tillers in 10-cm- and 20-cm-diameter gaps. Seedlings had more tillers in the largest gaps $(40 \mathrm{~cm})$ without root exclusion and in all sizes of gaps with root exclusion. Differences between gaps in light levels can explain the patterns of emergence. However, root exclusion was the major factor that increased seedling growth performance. These results confirm that $L$. chinensis is a gap-enhanced species and suggest that restoration of degraded grassland needs to ensure that large light gaps and low belowground competition are regularly maintained to maximize successful seedling recruitment.
\end{abstract}

\section{Resumen}

Se condujo un estudio de campo para investigar los efectos de los vecinos adultos existentes y el tamaño del los espacios vacíos en el proceso de establecimiento de plántulas de Leymus chinensis. En una estepa degradada del norte de China se crearon huecos artificialmente a los que se les agregó semilla de L. chinensis. La raíces de los vecinos se excluyeron usando tubos de PVC enterrados en el suelo de los huecos. La emergencia y supervivencia de las plántulas fue mayor en los huecos que en las áreas control. Cuando las raíces de los vecinos estuvieron presentes el crecimiento de las plántulas fue mayor solo en los huecos más grandes ( 20 y $40 \mathrm{~cm}$ de diámetro); en ausencia de raíces de los vecinos el crecimiento fue mayor en todos los huecos. En el área control las plántulas no produjeron hijuelos y en los huecos de 10 y $20 \mathrm{~cm}$ produjeron pocos. Las plántulas en los huecos más grandes $(40 \mathrm{~cm})$ tuvieron más hijuelos cuando no estuvieron excluidas de las raíces de los vecinos, misma respuesta que se obtuvo en todos los huecos con exclusión de raíces. Las diferencias entre huecos a niveles ligeros pueden explicar los patrones de emergencia, sin embargo, la exclusión de raíces fue el principal factor que aumentó el crecimiento de las plántulas. Estos resultados confirman que L. chinensis es una especie favorecida por la presencia de huecos y sugieren que para maximizar el éxito de establecimiento de las plántulas, la restauración de pastizales degradados necesita asegurar que se mantengan grandes huecos ligeros y una baja competencia entre raíces.

Key Words: competition, emergence, gap size, restoration, seedling growth

\section{INTODUCTION}

Leymus chinensis (Trin.) Tzvel. is a native perennial rhizomatous grass with good palatability and high forage value. Grasslands dominated by L. chinensis are widely distributed from the southern Chinese loess plateau (about lat $107^{\circ} 00^{\prime} \mathrm{E}$, long $34^{\circ} 00^{\prime} \mathrm{N}$ ) to the northern Russian Baikal (lat $107^{\circ} 40^{\prime} \mathrm{E}$, long $53^{\circ} 00^{\prime} \mathrm{N}$ ), and from the Sanjiang plain in eastern China (lat $135^{\circ} 05^{\prime} \mathrm{E}$, long $49^{\circ} 27^{\prime} \mathrm{N}$ ) to Ulan Bator (lat $106^{\circ} 53^{\prime} \mathrm{E}$, long

Research was funded by the National Proprietary Basic Research Program (973 program project, 2007CB106800) and the State "ShiWu" Key Project for Basic Sciences of "Key techniques research and demonstration on grassland vegetation restoration and reconstruction" (No. 2004BA528B01).

At the time of research, Liu was a doctoral student, Institute of Grassland Science, China Agricultural University, Yuanmingyuan Xilu 2, Haidian District, Beijing, 100094, China.

Correspondence: Jian Guo Han, Institute of Grassland Science, China Agricultural University, Yuanmingyuan Xilu 2, Haidian District, Beijing, 100094, China. Email: grasslab@ public3.bta.net.cn

Manuscript received 15 October 2006; manuscript accepted 7 August 2007. $47^{\circ} 55^{\prime} \mathrm{N}$ ) of Mongolia. This distribution of L. chinensis covers a range of climate from semiarid to subhumid (Wang et al. 1999). However, these grasslands have been degraded in recent decades due to land-use practices (e.g., over grazing, conversion to agricultural use, etc.), which have resulted in strong dust storms. Grassland protection and restoration in China is an urgent issue for the government and communities (Yang and Zhu 1995).

Reintroduction of $L$. chinensis has proven to be a highly effective management method for restoration of degraded grassland (Gao 2004; Zhao and Sun 2004). The fates of seedlings are critically important for successful restoration after reseeding. The early phase of seedling establishment is a vulnerable stage in the plant life cycle (Fenner 1985) and a critical period for successful species recruitment (Kitajima and Fenner 2000; Hofmann and Isselstein 2004).

Regeneration from seed in most plant communities is dependent upon the occurrence of gaps in the vegetation, sometimes of specific dimension, shape, and duration (Goldberg and Werner 1983; Fenner 1985; Kotanen 1997; Pakeman and 
Small 2005). Gaps provide conditions in which competition is reduced or absent (Fenner 1985; Bullock 2000), and they can provide regeneration niches for species recruitment (Hofmann and Isselstein 2004). Many species grow or survive better in gaps than in intact vegetation (Aguilera and Lauenroth 1995; Morgan 1997). The light, temperature, and moisture regimes in gaps are radically different from those in closed vegetation (Goldberg and Werner 1983; Bradshaw and Goldberg 1989; Morgan 1997; Jutila and Grace 2002). Creating conditions favorable for seedling establishment and survival is crucial for successful revegetation of degraded sites. Optimal gap sizes for successful seedling establishment can sometimes be larger than those typically occurring in habitats where the species is found, making successful recruitment from seed an occasional event and contributing greatly to rarity (Morgan 1997).

Three major constraints affect the seedling establishment of L. chinensis. First is a limitation associated with low seed availability. Seed production is variable and very low (Yang and Li 1994; Yang et al. 2001), and seedling recruitment is often seed-limited (Yang and Zhu 1995). Reestablishment of $L$. chinensis can thus depend on deliberate reintroduction of seed. Secondly, L. chinensis has a low seed germination percentage, even under favorable water and temperature conditions, because of seed dormancy (Yang et al. 2001). Third, seedlings derived from seeds sown into existing vegetation have low survivorship and poor growth performance due to competition from neighboring vegetation (Wang 2004). These constraints suggest that successful reestablishment of L chinensis could require seed addition and some level of disturbance.

Previous studies on the effect of management on L. chinensis reestablishment after reintroduction often refer to the resulting number of plants, the vegetation cover and aboveground biomass after a distinct period of time (Gao 2004; Zhao and Sun 2004). However, establishment of seedlings of L. chinensis in natural vegetation has not been evaluated, even though it is a critical step in the successful introduction of the species. Knowledge of the constraints on establishment can provide the basis for more efficient restoration management schemes. Our hypothesis is that competitive interactions with neighboring plants reduce the emergence and the growth performance of $L$. chinensis seedlings. We performed a field experiment to assess the effects of different gap sizes and of root exclusion on the emergence and early establishment of L. chinensis sown into a degraded steppe.

\section{MATERIALS AND METHODS}

\section{Study Site}

The experiment was conducted at the National Field Station of Grassland Ecosystem (NFSGE; lat $41^{\circ} 45^{\prime} \sim 41^{\circ} 57^{\prime} \mathrm{N}$, long $115^{\circ} 39^{\prime} \sim 115^{\circ} 48^{\prime} \mathrm{E}$, altitude $1350 \mathrm{~m}$ ), Saibei administrative region, Hebei province, China. The NFSGE is located in the southern part of the Xilingol steppe grassland. The climate of NFSGE is semiarid. Mean annual precipitation totals $399 \mathrm{~mm}$ and mainly occurs in July, August, and September. Differences in rainfall between the experimental year and the 20-year average values are shown in Figure 1. Mean annual temperature is $1.8^{\circ} \mathrm{C}$, and the accumulated temperature $\geq 10^{\circ} \mathrm{C}$ is $1513^{\circ} \mathrm{C}$. Average annual wind speed is $4.3 \mathrm{~m} \cdot \mathrm{s}^{-1}$. Annual

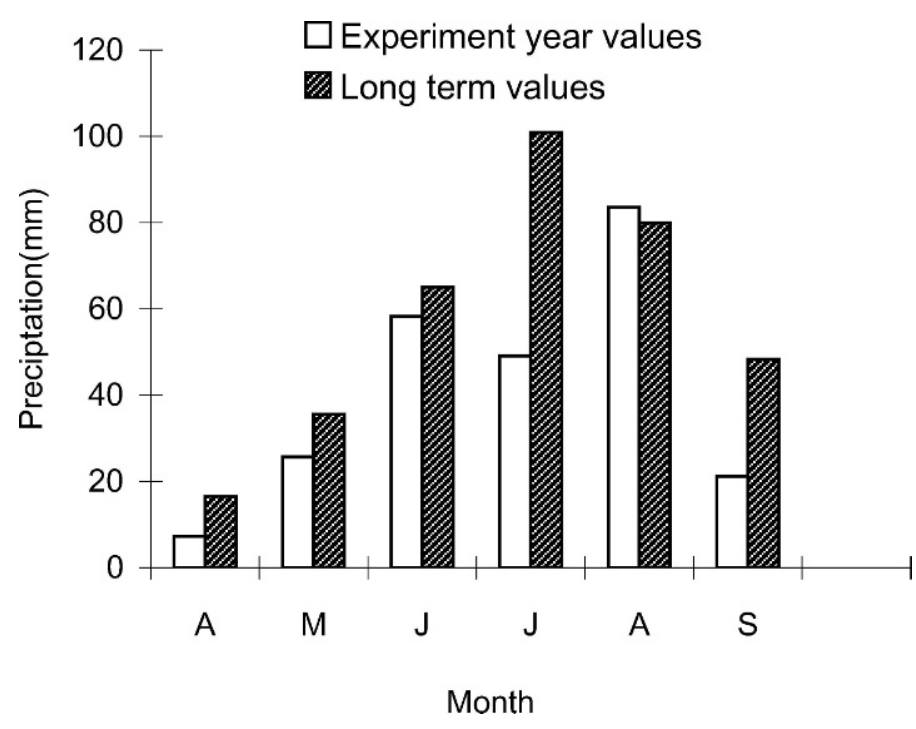

Figure 1. Mean monthly rainfall for the long-term (20-year) average and for the year of the experiment at Saibei Administrative Region Science and Technology Field, which was situated $500 \mathrm{~m}$ from the experimental sites.

sunshine duration is 2930 hours. The growing season lasts 100 days. The main soil type is Chestnut and a little alkaline ( $\mathrm{pH}$ 7.7). The site was dominated by forbs (Artemisia eriopoda Bunge, Artemisia tanacetifolia L., Saussurea amara [L.] DC., Potentilla tanacetifolia Willd. ex Schlecht.) and some grasses, including Cleistogense squarrosa (Trin.) Keng and Poa annua L. Also common were L. chinensis, Bromus inermis Leyss., and Agropyron cristatum (L.) Gaertn. (Zhang 2007).

\section{Experimental Design}

Seeds were collected from their natural habitat in the Saibei administrative region in the autumn of 2004. Seeds were air dried at room temperature, cleaned, and stored in paper bags. Each seed was examined by gently squeezing; it was used only if it was filled. Viability trials (Association of Official Seed Analysts 1988) used 400 filled seeds (average viability, $84 \%$ ), and all numbers used hereafter in the text refer to viable seeds.

The experiment was a randomized complete block design with eight blocks of $9.5 \times 0.5$ meters (three blocks were used for soil moisture testing). The two main factors were root exclusion and gap size. Root exclusion had two levels, exclusion and presence of neighboring roots. Gap size had three levels, with cleared aboveground diameters of $10 \mathrm{~cm}$, $20 \mathrm{~cm}$, and $40 \mathrm{~cm}$. We also examined one additional situation of no gap and no root exclusion as a control. The total of seven treatments was randomly distributed within each block on a regular $50 \mathrm{~cm}$ grid. The distance between blocks was $1 \mathrm{~m}$. We refer to a gap with the presence of neighboring roots as a "light gap," and a gap with neighboring roots excluded as a "root/light gap" (Bullock 2000).

In late May 2005, 48 gaps (16 replicates per gap size, with half of the gaps with the presence of neighboring roots and half with neighboring roots excluded) were created by cutting out and removing circles of vegetation of appropriate diameter and 
approximately $1.5 \mathrm{~cm}$ deep. Then a 25 -cm-deep layer of soil underlying the removed circles was removed and passed through a 2-mm soil sieve (removing plant roots, seeds, and other plant materials). For the treatment with neighboring roots present, holes were backfilled with the sieved soil and firmed until the new soil was flush with the existing ground surface. The root exclusion treatments were created by using polyvinyl chloride (PVC) tubes to exclude neighboring root systems (Cahill and Casper 2002; Hitchmough 2003). PVC tubes were installed with their tops flush with soil surface, then the holes were refilled with the removed soil until the new soil was flush with the PVC and firmed. Tubes had the same diameter as the gap size $(10 \mathrm{~cm}$, $20 \mathrm{~cm}$, and $40 \mathrm{~cm}$ ) and were $25 \mathrm{~cm}$ deep. Soil was not mixed within or between blocks. Plants other than $L$. chinensis that grew in gaps were removed by hand to maintain the gap size. For the control treatments (no light gap and neighboring roots present), all vegetation and soil was left intact and undisturbed.

On 11 June 2005, 20 seeds were sown into the center $(8 \mathrm{~cm}$ in diameter) of each gap or under the intact grassland canopy for the control $(8 \mathrm{~cm}$ in diameter) to a depth of $1-2 \mathrm{~cm}$. After seeding, the number of emerging seedlings was recorded daily until no new seedlings emerged. In addition, $10 \mathrm{~mm}$ of water was added weekly for 5 weeks, after which no new seedlings appeared. Soil water content was recorded biweekly after the cessation of watering. At the end of the growing season (90 days from seeding), we recorded seedling survival and height, number of leaves, and number of tillers for each surviving seedling. On five replicates of each treatment, we randomly selected two seedlings and harvested aboveground parts of surviving seedlings (in total, ten seedlings for each treatment). These samples were dried at $80^{\circ} \mathrm{C}$ for 48 hours and weighed. Throughout the experiment we used pesticides (malathion) to limit herbivory by invertebrates such as grasshoppers and flea beetles. The experiment also was performed in an enclosure to prevent damage to seedlings from trampling or grazing by domestic livestock.

\section{Soil Water and Microclimatic Conditions}

Gravimetric soil moisture in the 0-5- and 5-15-cm-depth increments was measured biweekly in the three blocks which were designated for soil water testing from July to September 2005. Soil samples were taken around the area sowed with $L$. chinensis seed (i.e., the 8-cm-diameter area at the center of each treatment, including the control) with a 2 -cm-diameter soil corer. Care was taken to minimize seedling disturbance. Soil samples were weighed to measure wet weight, dried at $105^{\circ} \mathrm{C}$ for 24 hours, and then weighed again to measure dry weight. Holes were refilled with soil taken from near the blocks and were marked with a colored peg to avoid resampling the same location. Soil temperature was measured weekly using ESS-T1 temperature sensors (Xinyuan Shijie Technology and Development Inc., Beijing, China) buried $5 \mathrm{~cm}$ deep. Precipitation was recorded weekly at a location adjacent to the study site from May to September 2005 using a 900ET Watch Dog portable weather station (Spectrum Technologies, Inc., Plainfield, IL).

Light intensity was measured $0,2,6$, and 10 weeks after sowing using a Li-COR Li-250A light meter (Li-COR Inc., Lincoln, NE) with quantum sensor to measure photosynthetic active radiation (PAR). Light levels were recorded at the center of each gap within 1 hour of solar noon on cloudless days from June to August 2005. In each treatment, two readings were taken: one was $2 \mathrm{~cm}$ above ground level and the other was above the canopy or vegetation (total light). Light availability was the ratio of $2 \mathrm{~cm}$ light intensity to total light, expressed as a percentage, to represent that experienced by seedlings.

\section{Statistical Analysis}

Response variables to quantify seedling emergence and performance were: number of seedlings per replicate at 40 days from seeding to characterize emergence; survivorship at 95 days from seeding (end of growing season) to characterize seedling survivorship; and height, number of leaves and tillers, and dry matter of individual seedlings at the end of the growing season to characterize seedling performance. Seedling survivorship was calculated as the number of seedlings alive at the end of the experiment divided by those that had emerged. Microclimatic variables were soil moisture, light intensity, and soil temperature. Seedling survivorship, soil moisture, light intensity, tiller number, and dry weight data were transformed to meet statistical assumptions of normality and variance homogeneity (Sokal and Rohlf 1981). Back-transformed means are reported where appropriate (Wirth and Pyke 2003).

Soil temperature data were analyzed at 2-week intervals. Light intensity was compared between all light gaps (including the control) at each date of recording with a single factor analysis of variance (ANOVA) similar to that used by Morgan (1997). All other statistical analyses were performed by fitting generalized linear models with the procedure of SPSS 12.0 (SPSS, Chicago, IL), and we used type III sums of squares for the calculation of $F$ statistics. The nested design ANOVA was used to test the main effects (data including all gap treatments and the control), where the effect of root exclusion was nested into treatments. We then carried out a second analysis of variance after removing the control treatments from the analysis to test the interaction on these parameters similar to that used by Aguilera and Lauenroth (1993). For the second analysis of variance, we used the 2-way ANOVA to examine the interaction effects on seedling emergence and growth performance variables (emergence, survivorship, height, leaves, tillers, and dry matter production per seedling), and repeated measures ANOVA to test the interaction effects on the soil moisture and temperature variables. Least significant difference multiple comparisons were used when a significant ANOVA was found.

\section{RESULTS}

\section{Emergence}

Emergence was observed in all gaps within 2 weeks of sowing and continued over the next 2 weeks. Most seedlings emerged within 3 weeks of sowing, and no emergence was recorded after the initial pulse of emergence. However, the first emergence time in the control treatment was about 4 days later than the other treatments. Across the experiment as a whole, $42 \%$ of the viable seeds that were sown emerged.

Data summarizing numbers of emerged seedlings to day 40 are shown in Figure 2A. Seedling emergence was significantly different among all gap sizes, including the control 
$\left(F_{3,28}=12.76, \quad P<0.001\right)$, with the number of emerged seedlings greatest in $40 \mathrm{~cm}$ gaps (16.7) and least in the control treatment (8.4). However, root exclusion did not significantly affect emergence $\left(\mathrm{F}_{3,28}=0.64, P=0.596\right)$ nor was the interaction between root exclusion and gap size significant $\left(\mathrm{F}_{2,24}=0.79, P=0.461\right)$.

\section{Seedling Survivorship}

At the end of the growing season, the effect of gap size on seedling survivorship was significant $\left(\mathrm{F}_{3,28}=13.77\right.$, $P<0.001$ ). However, root exclusion and the gap size-root exclusion interaction were not $\left(\mathrm{F}_{3,28}=0.09, P=0.964\right.$; $\mathrm{F}_{2,24}=0.10, P=0.905$, respectively). Seedling survivorship (Fig. 2B) was significantly higher in larger gaps $(20 \mathrm{~cm}$ and $40 \mathrm{~cm})$ than in smaller gaps $(10 \mathrm{~cm})$ and the control, but was not significantly different between the control and $10-\mathrm{cm}$ gap treatment nor between the $20-\mathrm{cm}-$ and $40-\mathrm{cm}$-gap treatments. Most of the seedlings that died were due to grazing by grasshopper and flea beetle after 7 days of emergence, even though pesticides were used to control invertebrate herbivores. The remaining seedlings died from desiccation in middle July after cessation of water addition.

\section{Seedlings Growth Performance}

At the end of the growing season, all seedling growth variables (leaves, tillers, height, and dry weight per seedling) were positively related to gap size (Figs. 2C-F). Gap size, root exclusion and their interaction affected dry weight of a seedling significantly $\left(F_{3,7}=2758, P<0.001 ; F_{3,7}=1279, P<0.001\right.$; and $F_{2,6}=276.6, P<0.001$, respectively). Seedlings growing in larger gaps produced more dry matter than seedlings in smaller gaps and the control (Fig. 2F). Mean shoot biomass per seedling in gaps was 7-180 times greater than the control. Seedlings growing in root/light gaps produced more dry matter than those growing in light gaps and the control.

Gap size and root exclusion affected the height and number of leaves and tillers of a seedling significantly (height: $\mathrm{F}_{3,63}=55.63, P<0.001 ; \mathrm{F}_{3,63}=48.97, P<0.001$, respectively; leaves: $\mathrm{F}_{3,63}=25.96, P<0.001 ; \mathrm{F}_{3,63}=3.36, P<0.05$, respectively; tillers: $F_{3,63}=16.09, P<0.001 ; F_{3,63}=9.78$, $P<0.001$, respectively), but there were no significant interactions between gap size and root exclusion (height: $F_{2,54}=2.39$, $P=0.101$; leaves: $\mathrm{F}_{2,54}=0.42, P=0.661$; tillers: $\mathrm{F}_{2,54}=0.32$, $P=0.729)$. Seedlings growing in larger gaps $(20 \mathrm{~cm}$ and $40 \mathrm{~cm})$ were taller than seedlings in smaller gaps $(10 \mathrm{~cm})$ and the control (Fig. 2C). All seedlings in gaps were taller than $14 \mathrm{~cm}$, which was 2-5 times greater that that of the controls. Seedlings growing in root/light gaps were taller than in gaps without root exclusion. Seedlings growing in gaps had more leaves than seedlings growing in controls (Fig. 2D). In general, seedlings growing in root/light gaps had more leaves than in gaps without root exclusion, but these differences were not statistically significant (Fig. 2D). Seedlings growing in root/ light gaps had more tillers than in gaps without root exclusion (Fig. 2E). No tillers were produced in the control. One seedling in a $40 \mathrm{~cm}$ root/light gap produced one inflorescence. Most seedlings, however, were too small to flower in their first growing season.

\section{Soil Water (Moisture)}

Seasonal changes in soil moisture at different depths were similar among each treatment (Figs. 3A and 3B). However, gap size, root exclusion, and their interaction affected soil moisture significantly both at $0-5 \mathrm{~cm}$ and $5-15 \mathrm{~cm}$ depth increments $(0-$ $5 \mathrm{~cm}: \mathrm{F}_{2,70}=4.55, P=0.014 ; \mathrm{F}_{2,70}=5.58, P=0.006$; and $\mathrm{F}_{2,12}=4.01, P=0.046$, respectively; $5-15 \mathrm{~cm}: \mathrm{F}_{2,70}=5.89$, $P=0.004 ; \quad \mathrm{F}_{2,70}=11.54, \quad P<0.001 ; \quad$ and $\quad \mathrm{F}_{2,12}=5.33$, $P=0.022$, respectively). Soil moisture was greatest in $20 \mathrm{~cm}$ and $40 \mathrm{~cm}$ gaps and least in $10 \mathrm{~cm}$ gaps and the control. Soil moisture in root/light gaps was higher than in gaps without root exclusion and the control. The seasonal pattern of soil moisture at $0-5 \mathrm{~cm}$ was significantly different from that at 5$15 \mathrm{~cm}\left(\mathrm{~F}_{24,70}=9.18, P<0.001 ;\right.$ and $\mathrm{F}_{24,70}=7.25, P<0.001$, respectively).

\section{Light Availability}

Effects of gap size on the light availability at the center of a gap varied significantly on all sampling dates $\left(\mathrm{F}_{3,11}=74.03,3058\right.$, 546.8 , and 260.1, respectively; all $P<0.001)$. Light availability was significantly greater in $20 \mathrm{~cm}$ and $40 \mathrm{~cm}$ gaps than in $10 \mathrm{~cm}$ gaps and the control (Fig. 4). Percentage of total light was not significantly different $(P>0.05)$ between $20 \mathrm{~cm}$ and $40 \mathrm{~cm}$ gaps at any dates of observation. In early summer (11 June), the difference in light availability between the $10 \mathrm{~cm}$ gap and control treatments was less marked, but these treatments were significantly different on other dates.

\section{Soil Temperature}

Gap size, root exclusion, and their interaction affected $5 \mathrm{~cm}$ soil temperature significantly $\left(\mathrm{F}_{2,98}=30.54, \quad P<0.001\right.$; $\mathrm{F}_{2,98}=11.50, P<0.001 ;$ and $\mathrm{F}_{2,12}=16.29, P<0.001$, respectively). The $5 \mathrm{~cm}$ soil temperature in root/light gaps was significantly higher than in gaps without root exclusion (Fig. 5). Differences between 10-cm and 40-cm gaps, between $20-\mathrm{cm}$ and $40-\mathrm{cm}$ gaps, and between the control and all other treatments were significant. For all measurements on all sampling dates, the highest top soil temperature occurred in the largest $(40-\mathrm{cm})$ root/light gap and the least always occurred in the control. The $5 \mathrm{~cm}$ soil temperature also varied seasonally $\left(\mathrm{F}_{36,98}=1.86, P=0.009\right)$, with soil temperatures of the different treatments within $1^{\circ}-2^{\circ} \mathrm{C}$ of each other on a cloudy day (i.e., on $9 \mathrm{July}$ ) and within $3^{\circ}-7^{\circ} \mathrm{C}$ on cloudless days (i.e., on 11 June and 20 August).

\section{DISCUSSION}

\section{Seed Emergence}

The number of seedlings that emerged in gaps was greater than in the controls. The percentage of emergence in the largest gaps (40 $\mathrm{cm}$ in diameter; $82 \%$ ) was close to what we observed when sowing seeds $1 \mathrm{~cm}$ deep in pots filled with field soil $(84 \%)$ and to what we observed in chamber germination tests $(84 \%$; Liu et al. 2007). However, emergence of all other treatments was considerably lower than in pot sowing or in germination tests. No obvious signs of seed predation were observed in the field. As in other studies (Hutchings and Booth 1996; Isselstein et al. 

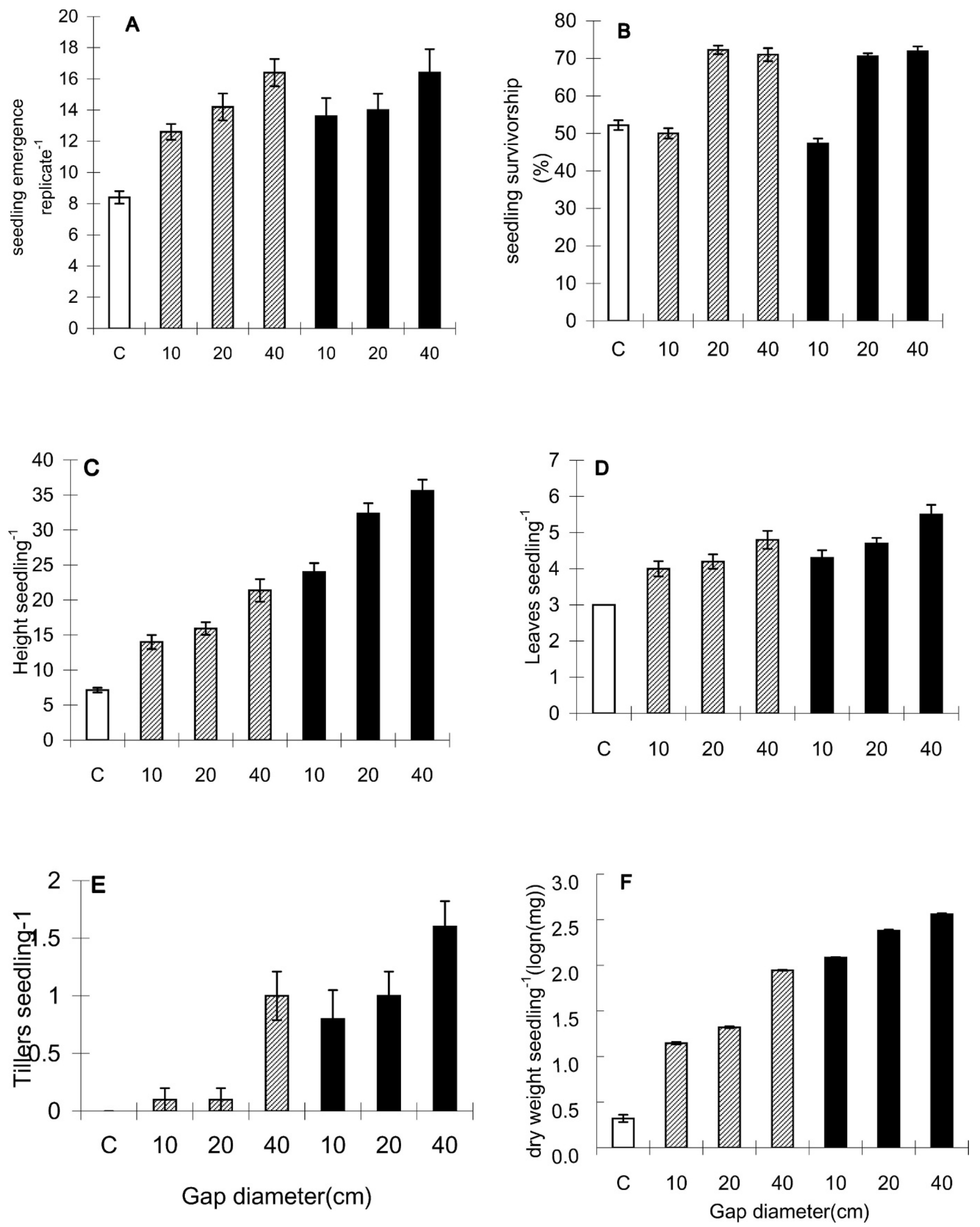

Figure 2. Effects of gap size and root exclusion on: A, number of emerged seedlings per replicate at 40 days after seeding; B, seedling survivorship at the end of the growing season (95 days from seeding); and $\mathbf{C}$, height, $\mathbf{D}$, number of leaves, $\mathbf{E}$, number of tillers, and $\mathbf{F}$, dry weight per seedling of Leymus chinensis at the end of the growing season. Seeding was on 11 June 2005. Bars represent treatment mean \pm SE. $\square$, control; $\mathbb{Z}$, light gap; 口, root/light gap. C indicates control. For light gap diameters: $10 \mathrm{~cm}$ (10), $20 \mathrm{~cm}$ (20), and $40 \mathrm{~cm}$ (40). For root/light gaps: neighboring roots excluded by polyvinyl chloride tubes. $n=5$ for emergence and survivorship; $n=10$ for height, leaves, and tillers; $n=2$ for dry weight. 

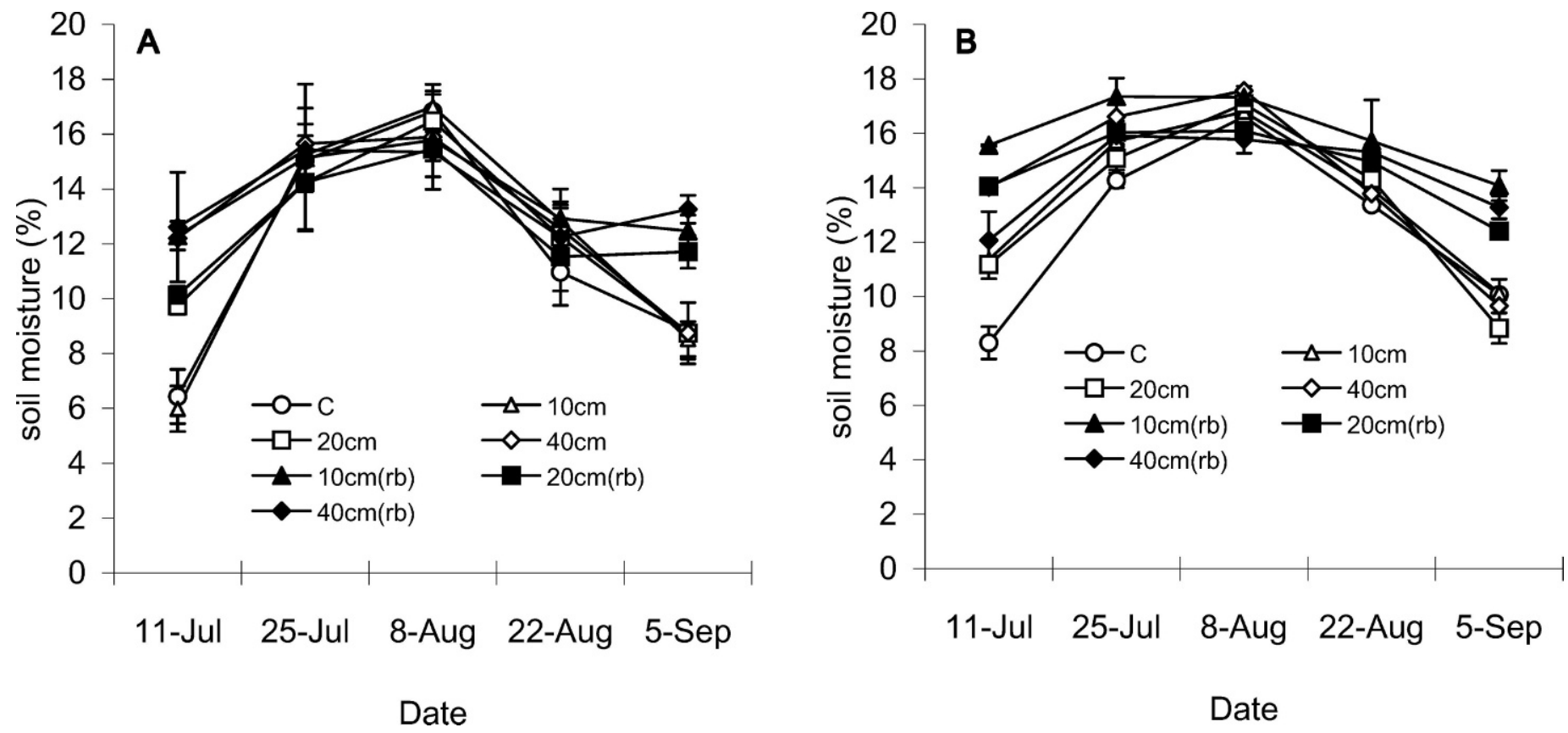

Figure 3. Changes in gravimetric soil moisture at: $\mathbf{A}, 0-5 \mathrm{~cm}$ and $\mathbf{B}, 5-15 \mathrm{~cm}$ depth increments for different gap size and root exclusion treatments from July to September 2005. Control plots are indicated by C; gap diameters by $10 \mathrm{~cm}, 20 \mathrm{~cm}$, and $40 \mathrm{~cm}$; and root gaps by rb. Bars represent \pm SE $(n=3)$.

2002), we assume that the difference between field and greenhouse germination was due to less suitable microenvironmental conditions in the field.

Average number of emerged seedlings in larger gaps $(40 \mathrm{~cm})$ was almost twice as high as in the controls. Light availability, $5 \mathrm{~cm}$ soil temperature, and soil moisture were higher in gaps than in the controls. The higher light availability in gaps probably had an important influence on the increased emergence. In addition, higher emergence in the gap plots than in the control plots might be due to increased nutrient

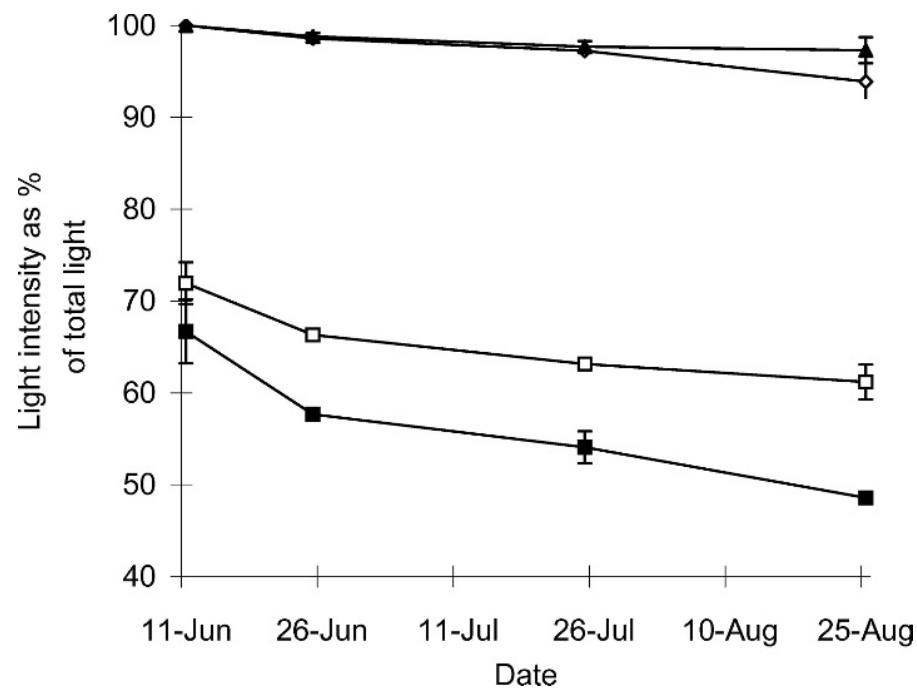

Figure 4. Changes in light availability at the center of gaps (expressed as a percentage of the total light available above the canopy) from June to August 2005. $\mathbf{\square}$, control; gap diameters: $\square 10 \mathrm{~cm}, \diamond 20 \mathrm{~cm}$, and $\boldsymbol{\Delta}$ $40 \mathrm{~cm} ; n=3$. availability from soil disturbance during setting up the gap plots. Other studies show that imbibed seeds in an environment with light and alternating temperatures can stimulate germination (Thompson and Grime 1983), and this response is recognized as a gap-detecting mechanism (Thompson et al. 1977; Fenner 1985). Hofmann and Isselstein (2004) found that the soil surface disturbance by harrowing or raking before spreading grassland seeds provided the optimal environmental cues to trigger germination and promoted seedling emergence.

Gap size had the most stimulating effect on seedling emergence compared with the root exclusion treatments. Similar results were obtained in a broad range of herbaceous vegetation

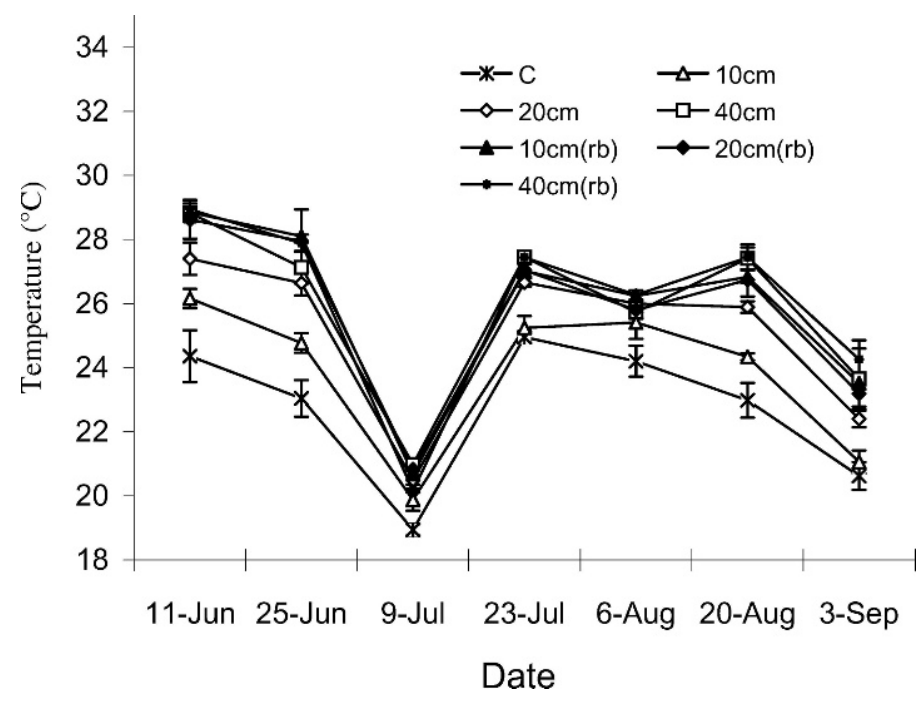

Figure 5. Temperatures in the top $0-5 \mathrm{~cm}$ of soil under the different treatments $(n=3)$. For symbol explanations, see Figure 3 . 
(Aguilera and Lauenroth 1993; Bullock et al. 1994; Morgan 1997). However, a few studies indicate that seedling emergence was not affected by presence of a gap (compared with closed vegetation) or gap size (Goldberg and Werner 1983; Hitchmough 2003). Gill and Marks (1991) even found a negative effect of light gap on emergence of shrubs in an old field.

Root exclusion had no significant effect on seedling emergence, probably because it did not affect light availability, although the $5 \mathrm{~cm}$ soil temperature was higher in root/light gaps than in gaps without root exclusion. Many other studies, however, have reported that root gaps significantly increase seedling emergence (Aguilera and Lauenroth 1993; Moretto and Distel 1998). These literature results occurred when water was probably the main limiting resource. For example, Aguilera and Lauenroth (1995) found that gaps in a semiarid steppe community increased soil moisture levels. In our study, we observed that soil moisture in root/light gaps was higher than in gaps without root exclusion at the time of emergence, but emergence of $L$. chinensis did not increase. Thus, our results cannot be attributed to differences in soil moisture.

\section{Seedling Survivorship and Growth Performance}

Gap size enhanced the seedling survival of $L$. chinensis. The larger gaps $(20 \mathrm{~cm}$ and $40 \mathrm{~cm}$ ) had higher survivorship than the smallest gaps $(10 \mathrm{~cm})$ and the controls. Other experiments also show similar results of increased survival of emerged seedlings in light gaps as compared with the controls (McConnaughay and Bazzaz 1987; Aguilera and Lauenroth 1993; Bullock et al. 1994), and often higher survival in larger gaps (Aguilera and Lauenroth 1993; Morgan 1997). However, survivorship has been reported as higher in smaller gaps (Burke and Grime 1996) and even as no difference between gaps and intact vegetation (Hanley 2004). O'Connor (1996) found that seedling survivorship of Themeda triandra (Forssk.) was decreased by light gaps unless water was added, which was likely caused by light in canopy gaps decreasing soil moisture in the arid environment. In contrast, seedling survivorship of $L$. chinensis was not affected by root exclusion. Our result did not conform to other studies (Aguilera and Lauenroth 1993, 1995; Moretto and Distel 1998) that showed that root gaps were necessary for seedling survival.

Seedling growth performance appears to be sensitive to both above- and belowground competition, but especially to belowground competition. L. chinensis emerged in all gap sizes and in intact vegetation, but grew more in the largest gaps $(40 \mathrm{~cm})$ and in root/light gaps as indicated by greater tiller production, taller seedling height, and greater dry weight production per seedling. Interestingly, all seedlings in root/light gaps had higher growth performance than in gaps without root exclusion, regardless of the gap size. Competition for physical space and soil nutrients might be the key factors that limit the establishment of L. chinensis. McConnaughay and Bazzaz (1991) suggested that the presence of roots in the soil might be important not only in depleting water and nutrients, but also in creating physical barriers to root growth. A root gap might therefore provide a physical space for seedling establishment as well as an area of reduced resource competition. Cahill and Casper (2002) showed that gaps provided areas of low belowground competitive intensities.

\section{MANAGEMENT IMPLICATIONS}

Previously-reported constraints associated with seed-based regeneration of $L$. chinensis include low seed germination percentage and unfavorable temperature and water conditions for seedling establishment. Competition from adult neighbors is an additional constraint that negatively affects emergence and performance of seedlings. Seedlings of $L$. chinensis are vulnerable to competitors before they produce tillers. Seedlings can compete with the established plants after they produce tillers and rhizomes (Jia 1987), and some studies suggest that seedlings of $L$. chinensis that had produced tillers could compete with weeds (Zhu 2004; Jia 1987). Once it recruits successfully, L. chinensis can become the dominant component in communities because of its vigorous vegetative regeneration (Zhu 2004). Our study showed that only in the largest light gap $(40 \mathrm{~cm})$ and in all sizes of root/light gaps did seedlings produce more than one tiller. Thus, the suitable light gap for seedling establishment might be no less than $40 \mathrm{~cm}$.

The strong size-asymmetric interaction between adult neighbors and seedlings would occur when infrequent establishment events are triggered by the release of environmental constraints. Existing gaps of bare soil that are occupied by roots of neighboring plants probably would not be colonized by $L$. chinensis seedlings over long time periods. Disturbances that produce a gap in belowground space can provide conditions with reduced competition from established plants, which in turn increases the probability of successful seed regeneration of L. chinensis. Thus, in order to maximize restoration success of degraded grassland by reintroducing $L$. chinensis, large light gaps and low belowground competition should be provided.

\section{ACKNOWLEDGMENTS}

We thank Robert S. Nowak and two anonymous referees for their valuable comments on an early draft of this manuscript; Deng XueMei and Li ShouTian for their statistical suggestions; and Zhao Xia, Sun YueChun, and Li YuGang for their work during the experiment.

\section{LITERATURE CITED}

Aguilera, M. 0., and W. K. Lauenroth. 1993. Seedling establishment in adult neighbourhoods-intraspecific constraints in the regeneration of the bunchgrass Bouteloua gracilis. Journal of Ecology 81:253-261.

Aguilera, M. O., And W. K. Lauenroth. 1995. Influence of gap disturbances and type of microsites on seedling establishment in Bouteloua gracilis. Journal of Ecology 83:87-97.

Association of Official Seed Analysts. 1988. Rules for testing seeds. Lansing, MI: Association of Official Seed Analysts. 123 p.

Bradshaw, L., and D. E. Goldberg. 1989. Resource levels in undisturbed vegetation and mole mounds in old fields. American Midland Naturalist 121:176-183.

BuLlock, J. M. 2000. Gaps and seedling colonization. In: M. Fenner [ED.]. Seeds. The ecology of regeneration in plant communities. Wallingford, UK: CABI Publishing. p. 375-395.

Bullock, J. M., H. B. Clear, J. Silvertown, and M. Sutton. 1994. Gap colonization as a source of grassland community change: effects of gap size and grazing on the rate and mode of colonization by different species. Oikos 72:273-282.

Burke, M. J., And J. P. Grime. 1996. An experimental study of plant community invasibility. Ecology 77:776-790.

Cahill, J. F., and B. B. Casper. 2002. Canopy gaps are sites of reduced belowground plant competition in a productive old field. Plant Ecology 164:29-36. 
Fenner, M. 1985. Seed ecology. London, UK: Chapman and Hall. 37 p.

GAO, J. L. 2004. Research report on improving, regenerating and managing techniques of Xiashitan grassland. Pratacultural Science 21:6-8.

GILL, D. S., AND P. L. Marks. 1991. Tree and shrub seedling colonization of oldfields in central New York. Ecological Monographs 61:183-205.

Goldberg, D. E., and P. A. Werner. 1983. The effects of size of opening in vegetation and litter cover on seedling establishment of goldenrods (Solidago spp.). Oecologia 60:149-155.

Hanley, M. E. 2004. Seedling herbivory and the influence of plant species richness in seedling neighbourhoods. Plant Ecology 170:35-41.

Hiтснмочgh, J. D. 2003. Effects of sward height, gap size, and slug grazing on emergence and establishment of Trollius europaeus (Globeflower). Restoration Ecology 11(1):20-28.

Hofmann, M., AND J. ISSELSTEIn. 2004. Seedling recruitment on agriculturally improved mesic grassland: the influence of disturbance and management schemes. Applied Vegetation Science 7:193-200.

Hutchings, M. J., AND K. D. Booth. 1996. Studies of the feasibility of re-creating chalk grassland vegetation on ex-arable land. II. Germination and early survivorship of seedlings under different management regimes. Journal of Applied Ecology 33:1182-1190.

Isselstein, J., J. R. B. Tallowin, and R. E. N. Smith. 2002. Factors affecting seed germination and seedling establishment of fen-meadow species. Restoration Ecology 10:173-184.

JIA, S. X. 1987. Chinese grassland and forage plants records. Beijing, China: Agricultural Press. $34 \mathrm{p}$.

Jutila, H. M., and J. B. Grace. 2002. Effects of disturbance on germination and seedling establishment in a coastal prairie grassland: a test of the competitive release hypothesis. Journal of Ecology 90:291-302.

Kotanen, P. M. 1997. Effects of gap area and shape on recolonisation by grassland plants with differing reproductive strategies. Canadian Journal of Botany 75:352-361.

KitAuma, K., And M. Fenner. 2000. Ecology of seedling regeneration. In: M. Fenner [ED.]. Seeds. The ecology of regeneration in plant communities. Wallingford, UK: CABI Publishing. p. 331-360.

LiU, G. X., J. G. Han, and X. Zhao. 2007. Effects of sowing depth and seed source on the seedling emergence of Leymus chinensis. Agricultural research in the arid areas 75(5):69-74.

McConnaughay, K. D. M., and F. A. Bazzaz. 1987. The relationship between gap size and performance of several colonizing annuals. Ecology 68:411-416.

McConnaughay, K. D. M., and F. A. Bazzaz. 1991. Is physical space a soil resource? Ecology 72:94-103.
Moretto, A. S., And R. A. Distel. 1998. Recruitment of vegetation gaps for seedling establishment of two unpalatable grasses in a native grassland of central Argentina. Australian Journal of Ecology 23:419-423.

Morgan, J. W. 1997. The effect of grassland gap size on establishment, growth and flowering of the endangered Rutidosis leptorrhynchoides (Asteraceae). Journal of Applied Ecology 34:566-576.

O'ConnoR, T. G. 1996. Hierarchical control over seedling recruitment of the bunchgrass Themeda triandra in a semi-arid savanna. Journal of Applied Ecology 33:1094-1106.

Pakeman, R. J., and J. L. Small. 2005. The role of seed bank, seed rain and the timing of disturbance in gap regeneration. Journal of Vegetation Science 16:121-130.

Sokal, R. R., and F. J. Rohlf. 1981. Biometry. New York, NY: W. H. Freeman. $859 \mathrm{p}$.

Thompson, K., And J. P. Grime. 1983. A comparative study of germination response to diurnally-fluctuating temperatures. Journal of Applied Ecology 20:141-156.

Thompson, K., J. P. Grime, And G. Mason. 1977. Seed germination in response to diurnal fluctuations of temperature. Nature 267:147-149.

Wang, D. L., Z. W. Wang, and X. J. Zhang. 1999. The comparison of photosynthetic physiological characteristics between the two divergent Leymus chinensis types. Acta Ecological Sinica 19:837-843.

Wang, K. 2004. Grassland rehabilitation and reconstruction. Beijing, China: Chemical Industry Press. $35 \mathrm{p}$.

Wirth, T. A., And D. A. PYke. 2003. Restoring forbs for sage grouse habitat: fire, microsites, and establishment methods. Restoration Ecology 11:370-377.

YanG, Y. G., Y. M. Guo, Y. Guo, And J. X. Lin. 2001. Research advances on seed production and enhance seed germination of Leymus chinensis. Seed 5:40-42.

Yang, Y. F., AND J. D. LI. 1994. Effects of different utilization methods on reproductive characters of Aneuolepidium chinense. Grassland of China 5:34-37.

YANG, Y. F., AND L. ZHu. 1995. Comparative analysis of seed banks in saline-alkali communities in the Song-nen plain of China. Acta Phytoecologica Sinica 19:144-148.

ZHANG, H. S. 2007. Effects of enclosuring and shallow ploughing improvement on the vegetation restoration and soil physical and chemical properties in degraded Leymus chinensis grassland [dissertation]. Beijing, China: China Agricultural University. $23 \mathrm{p}$.

Zhaо, M. Q., AND J. L. Sun. 2004. Degraded situation and rehabilitation methods of Jiangjiadian grassland in Jilin province. Pratacultural Science 21:46-48.

Zнu, T. C. 2004. Leymus chinensis biological ecology. ChangChun, China: JiLin Science and Technology Press. 20 p. 